\title{
40
}

\section{Trust, culture and the limits of management-based regulation: Lessons from the mining industry}

\section{Neil Gunningham and Darren Sinclair}

\section{Introduction}

For over a decade, private enterprise and governments in North America, Western Europe and Australasia have been experimenting with an innovative approach to standard-setting variously termed 'process-based', 'systems-based' or 'management-based' regulation (Coglianese and Lazar 2003). In contrast with traditional prescriptive standards (which tell duty holders precisely what measures to take) or performance standards (which specify outcomes or the desired level of performance), this approach involves firms developing their own process and management system standards and developing internal planning and management practices designed to achieve regulatory or corporate goals. Such standards - whether they are imposed by the firm on its various operations (internal regulation), by governments on firms or by industry associations on their members (external regulation)- have the considerable attractions of providing flexibility to enterprises to devise their own least-cost solutions to social challenges, of facilitating their going beyond compliance with minimum legal standards and of being applicable to a broad range of circumstances and to heterogeneous enterprises. 
For present purposes, such initiatives will be termed 'management-based regulation'. This form of regulation is now to be found in a diversity of policy domains including environmental protection, food safety, occupational health and safety (OHS), rail regulation, sustainable forestry, toxic chemical reduction and trades practices (Coglianese and Lazar 2003; Coglianese and Nash 2006).

Taken one step further, management-based regulation can become a form of meta-regulation or 'meta risk management'. In this form, government (or a corporation seeking to regulate its multiple facilities), rather than regulating directly, risk manages the OHS management of individual enterprises or facilities. Under such an approach, the role of regulation ceases to be primarily about inspectors or auditors checking compliance with rules, and becomes more about encouraging the industry or facility to put in place processes and management systems that are then scrutinised by regulators or corporate auditors to ensure their appropriateness and effectiveness. Rather than regulating prescriptively, meta-regulation seeks to stimulate modes of self-organisation within the firm in such a way as to encourage proactive internal self-critical reflection about its performance (Parker 2002; Grabosky, Chapter 9, this volume).

So how effective are management-based and meta-regulation? Are government regulators or corporate decision-makers wise to put so many of their eggs into this basket? To the extent that this form of regulation falls short of expectations, is this inevitable or can its shortcomings be overcome? And what is the relationship between managementbased regulation and organisational trust? Is it the case, as some have claimed (Gunningham and Sinclair 2009), that 'culture eats systems for breakfast'? These and related questions will be addressed below.

\section{Management-based regulation: What the literature tells us}

At their best, management-based initiatives have the capacity to influence the internal self-regulation and norms of organisations and make them more proactive and responsive (rather than merely reactive) to social concerns. In theory, they will encourage enterprises to 'build 
in' regulatory considerations at every stage of the production process, to improve their social performance and to achieve behavioural change (Coglianese and Nash 2006: 250).

However, to what extent these theoretical benefits will be realised in practice is a matter for empirical inquiry. Such inquires have to date produced rather mixed results (Bluff 2003; Coglianese and Lazar 2003: 724). Some studies have found a positive relationship between the introduction of management systems and environmental outcomes (Thomas 2011); others have not (Tyteca et al.2002; Hertin et al.2008) leading an edited collection concerned to understand how managementbased initiatives have worked to date to conclude that 'we know little about the conditions in which' management-based initiatives work (Coglianese and Nash 2006: 20).

There could be a variety of reasons for these mixed results. Some companies may have adopted such systems (which in environmental protection are usually voluntary) for cosmetic reasons-such as to maintain public legitimacy-rather than to substantively improve performance. If that is the case, the principal problem may be not with the system itself, but with the motivations of those who adopt it. Indeed, it may be that management systems, like other process-based tools, are just that - tools—and they can only be effective when implemented with genuine commitment on the part of management and ownership on the part of the workforce. In short, it may be that management matters far more than management systems or management-based strategies more broadly.

This, however, should not lead to a focus simply on individual members of management because much organisational behaviour is group behaviour, and, in the context of the corporation, it is more fruitful to explore compliance with rules (whether corporate or state based) at the collective rather than the individual level.

In this context, one factor that can have a particularly powerful impact on group behaviour in general and on rule compliance in particular is organisational culture-defined as 'the way we do things around here' or, in more formal terms, as involving 'shared values (what is important) and beliefs (how things work) that interact with a company's people, organizational structures and control systems to produce behavioural norms' (Uttal 1983, in Reason 1997: 192). However, not infrequently, the beliefs and values of those who are expected to implement 
a management system are not congruent with its aspirations, in which case edicts from regulators or (in the case of internal regulation) from senior management may be met with creative compliance (McBarnet and Whelan 1999), resistance, 'ritualism' (Merton 1968; Braithwaite 2008: 140-56) or various other forms of tokenism.

Trust is one aspect of culture that is often of great significance, particularly in areas of social regulation such as the environment or OHS. According to the literature, for example, effective worker participation is crucial to improved OHS. However, such participation is unlikely to be effective in the absence of constructive dialogue between employers and employees (Gallagher 1997: 6.2). Constructive dialogue, in turn, is unlikely to take place in the absence of trust. Trust is often referred to as the lubricant for open and frequent safety communication (Reason 1997), as enhancing cooperation (Morgan and Hunt 1994), promoting the acceptance of decisions (Tyler 2003), improving knowledge sharing (Dirks and Ferrin 2002), supporting all aspects of organisational functioning (Bijlsma and Koopman 2003) and resulting in enhanced safety performance (Barling and Hutchinson 2000: 77). Trust can therefore become a central issue for social regulation in areas such as OHS.

The above literatures raise issues that go to the heart of the question: to what extent can management-based regulation achieve business or regulatory goals? This, in turn, raises the questions: Are policymakers, trade associations and corporations mistaken in their belief that those required to develop and implement plans, systems and other management-based strategies will improve their performance as a result? Is reliance on monitoring, measuring, accountability and extrinsic motivation misplaced? Might it be that management commitment or culture (or specific cultural issues such as trust) is far more important to achieving desired outcomes than management-based initiatives alone?

In the following section, we explore the above issues through the lens of OHS management and regulation in the Australian coalmining industry, summarising the implications of empirical research we undertook within two large coalmining corporations. Limitations of space, however, preclude a fuller description of the research itself or of our methodology. These can be found elsewhere (Gunningham and Sinclair 2012). 


\section{Mine safety in Australia: Management- based regulation and its consequences}

Although the mining industry confronts a number of serious OHS challenges, since the 1990s, statistics (which it is unlikely can be manipulated, including fatality statistics) suggest it has achieved substantial improvements in safety (Galvin 2005). This has coincided with an increased corporate focus on management-based initiatives as the central means of improving OHS, with a heavy emphasis on sophisticated systems, auditing and other process-based mechanisms. Indeed, such systems are now a regulatory requirement in the two principal coalmining jurisdictions of Australia: New South Wales and Queensland.

Below, we describe the findings of two case studies, designed to examine the experiences of two mining companies that, for various reasons, have relied substantially on management-based regulation to attempt to achieve improvements in their OHS performance or to meet regulatory requirements. While the two companies have different histories and management philosophies, there are similarities in how they sought to address OHS and in the outcomes they achieved. Either because they were driven by corporate concerns to improve OHS (Minerals Inc.) or by a combination of growing pains, peer pressure and government regulation (Coal Company), they relied heavily on a range of management tools to achieve their objectives.

In the language of this chapter, they relied substantially on either internally or externally driven management-based regulation with a particular emphasis on OHS management systems, standards and audits. Yet, notwithstanding the virtues of this approach, in practice, they both struggled, often unsuccessfully, to implement management-based regulation and, through it, to improve OHS outcomes. Why was this so?

A lack of organisational trust was certainly one of the most important problems, for our evidence shows that, without trust, the effectiveness of management-based regulation may be severely and sometimes fatally compromised. The most striking lack of trust at Minerals Inc. was between workers and management. At their worst-performing mines, such mistrust was deep-seated and longstanding. The reasons for this often related indirectly to the adversarial and bitter history of the mining 
industry, and directly to past site-specific incidents in which workers felt betrayed by management. Geographic isolation, parochialism and high management turnover sometimes exacerbated these problems.

But, as the Coal Company study reveals, a lack of trust between other groups was sometimes equally, if not more, important. We found corrosive mistrust between a variety of parties: corporate and mine site management; workers and middle management on one hand and senior mine management on the other; one group of workers and another; and middle management and the mine manager. We also found that corporate management can have its own distinctive culture, being locked into past practices and beliefs, and seemingly incapable of adjusting to the needs of managing an increasingly complex organisation. Within this mindset, corporate management at Coal Company were the ones who lost the trust of mine management.

All this suggests that trust-one important manifestation of workplace culture - needs to be understood not at the company level, and often not even at the mine-site level (although, in some respects, different mines do have distinctive cultures), but rather at the level of subcultures (and sometimes countercultures) that manifest themselves within different groupings within individual mines. These are what are likely to contain the most deep-seated values and norms, which are most likely to shape behaviour in general and the effectiveness of management-based regulation in particular.

At both companies, organisational mistrust was generated not just by local factors (such as how workers were treated by mine management), but also by broader factors (such as the adversarial history of mining). These factors commonly interacted, generating perceptions that often amplified mistrust and shaped behaviour. For example, where there was a history of mistrust then all management action on OHS (however genuine) was likely to be dismissed by the workforce as insincere. This resulted in a lack of commitment to management's OHS initiatives - a classic illustration of Thomas and Thomas's (1928) dictum that what is perceived to be real is real in its consequences.

An overlapping but distinctive theme was the conflict of loyalties experienced by different levels of management within the mine site hierarchy. This was most graphically illustrated by the experience of deputy under-managers (the lowest level of management), who, in both companies, felt torn between their obligations as members 
of management and their loyalties to their crew 'mates' as colleagues. To a lesser extent, other levels of management experienced the same tension-as, for example, where middle management sided with the workforce against the mine manager or where mine managers, while conscious of their obligations to corporate management, nevertheless felt acutely the needs of their own mine and of their own management team and workforce. This, too, had a negative influence on the effectiveness of management-based regulation.

A further theme was that a failure to obtain commitment from and engagement of middle management and the workforce was detrimental to implementation of management-based initiatives. This, too, was related to trust, though more so with workers than middle management. Our interviews suggested that lack of engagement was a particular problem with regard to the latter. Workers, already burdened with a range of duties and demands on their time, commonly viewed the additional requirements of applying management-based regulation as yet one more imposition. Importantly, they could not see the need for the imposition. They perceived that there were ulterior motives ('they want to cover their arse') and, as a result, they resented complying with the directions.

Finally, and closely related to the previous themes, there was the issue of unequal power. Workers often felt vulnerable and threatened by management initiatives. Increasingly pressured into individual contracts of employment, they are often unable to advocate collectively through trade unions capable of acting as a countervailing force. Middle management, too, feared that management-based regulation might be a means of placing them under greater senior management scrutiny and control. Deputy under-managers' allegiance often remained with the crew from which they had come. They felt uncertain whether higher management would support any safety initiatives they undertook or whether they would be 'hung out to dry'. In an industry with such an acrimonious history, such issues were never far from the surface. As we will see, they were particularly prone to arise in the situation where the tension between 'safety and profit' was most stark: deciding whether to halt production on safety grounds.

The most common response by both workers and middle management to mistrust, divided loyalties, lack of commitment (the three characteristics often being related) and/or a perception of powerlessness was ritualism. They would go through the motions without any conviction that this would achieve anything of substance. For example, participation in 
behavioural-based safety programs was perfunctory (particularly for those based on supervisor/subordinate observations), incident reporting was trivialised or ignored, systems were honoured more in the breach and sophisticated electronic monitoring systems were sidetracked.

It will be apparent that ritualism and resistance are unlikely to be overcome-or management-based regulation to succeed-in the absence of engagement with the culture or, more accurately, the various subcultures identified above. Cultural change is never easy to achieve. Indeed, some organisational theorists have argued that an organisation may be incapable of shaping its own culture (Schein 1983), while others argue that 'you only meddle with organisational culture if you've got little choice, lots of resources and lots of time' (Sinclair 1993: 68). However, we disagree with these pessimistic conclusions. In our case studies, the top OHS ranked mine sites of both enterprises shared a cluster of characteristics-largely as a result of strategic management intervention. While not all these characteristics were present at all these mines, the more of these characteristics that were present, the more likely a mine was to have minimised mistrust, to have overcome divided loyalties and a lack of buy-in and to have achieved a high OHS performance. Accordingly, our findings are consistent with the general approach of Reason (1997), who suggests that safety culture is actually a product of various interdependent subcultures, and that these can be socially engineered to a significant extent.

Among the cluster of characteristics we identified as important in overcoming mistrust, four, in particular, must be emphasised. First, there was strong evidence that organisational trust was strongly influenced by the extent to which the mine manager (the visible manifestation of 'the corporation' at site level) was genuinely committed to OHS improvement. This seemed to be a particularly important indicator of managerial leadership. At one high-ranking mine, for example, workers and middle managers spoke highly of the mine manager's leadership role. They said he engaged with the workforce, he did 'lots of things to be seen around the workforce-and chase[d] up all the complaints' (crew member). Crucially, he was willing to place OHS ahead of production, to the extent of shutting down the mine (at great expense) to address a safety issue. In contrast, at low-performance, low-trust mines, there were widespread complaints concerning management's willingness to cut corners and sacrifice safety to maximise production. 
Second, a common refrain-which resonates with Tyler's work (2003; see also Murphy, Chapter 3, this volume) concerning the importance of procedural fairness-was the preference that workers had for a mine manager who 'gives it to us straight' (as one crew member put it). As long as workers' complaints had been heard and investigated, and they had received feedback (even when being told that no further action would be taken), their levels of acceptance and trust were high. Workers (and deputies) at many lower-performing mines, however, expressed their frustration with what they perceived as conflicting messages and the inconsistent responses and attitudes of different managers.

Third, workers seemed far more likely to 'take on board' and implement OHS initiatives if they had a high degree of ownership of them. This was achieved by engaging them in the creation of these initiatives, or, in the case of corporate initiatives, by involving them in how these policies were interpreted and adopted at individual mine sites. Perhaps the best illustration concerns an attempt by management to introduce behavioural-based safety observations-usually resisted by the workforce because it is seen as a 'blame the worker' approach. Yet such an initiative was enthusiastically adopted at one mine. This was primarily because a high-status and influential group of miners was engaged at an early stage and came to feel that it was 'their' initiative.

Finally, it is striking that the strategies that corporate management relied on under management-based regulation-namely, an emphasis on accountability mechanisms that make it difficult for managers to avoid their OHS responsibility, coupled with surveillance, various performance tracking devices and auditing aimed at transparencywere antithetical to measures that our findings suggested had a positive impact on OHS. We found that in imposing stringent oversight and control, accountability and discipline, corporate management risks a number of counterproductive consequences. For example, the use of surveillance systems:

has deleterious effects on the social climate of groups. The use of surveillance implies distrust which decreases people's ability to feel positive about themselves, their groups and the system itself. (Tyler 2008: 810)

This, in turn, lowers motivation, creates an adversarial relationship and encourages the sort of resistance and ritualism described earlier. 
What made a difference, in the best OHS performing mines in our sample, were various mechanisms that provided workers and site management with more, rather than less, autonomy and discretion. These were the various approaches that served to gain worker or middle management commitment. They provided greater ownership of and participation in OHS initiatives, which involved greater communication and feedback. This involved providing deputies and middle management with greater training, mentoring and managerial support (albeit not control). Collectively, these actions served to gain or regain trust. The key is to ensure that informal systems 'support the formal system by enhancing cohesion, initiative and morale' (Selznick 1992: 235). Only in this manner may the gap between formal regulation and informal local norms be successfully bridged.

In short, trust and a number of related factors are vital in obtaining the consent and support of managers and workers to win their intrinsic motivation'. Once these groups accept and take ownership of the rules and regard them as reasonable and their purpose laudable, compliance becomes a matter of voluntary cooperation. People follow not just the letter, but also the spirit of management-based regulation and external monitoring costs become low. Workers and managers become 'active participants in creating and maintaining conditions of social order' (Tyler 2008: 873). This is largely irrespective of surveillance and other external controls. In Reason's (1997) terminology, it becomes possible to build in a culture of 'mindfulness'. This is not to imply that managementbased regulation has no value. It remains an important technology of governance, but one that can only work effectively in tandem with a supportive workplace culture built on trust, engagement and commitment.

\section{Conclusion}

Many regulators and corporations have concluded that managementbased regulation has considerable promise, particularly in encouraging enterprises to take greater responsibility for developing their own systemic approaches to regulatory or business challenges, and to create their own best means of identifying and managing risks. Nevertheless, to what extent or in what circumstances this promise will be realised in practice remains largely an open question. This is particularly so when it comes to applying management-based regulation to the multiple facilities of large corporations. 
Our case studies suggest that, in the mining industry at least, management-based regulation was vulnerable to failure for a variety of often interrelated reasons. At Minerals Inc., this approach was applied across the corporate portfolio, but it proved far more effective at mines where levels of trust between workers and management were higher. Moreover, management-based regulation was sometimes unable to overcome a combination of mine management resistance, middle management inertia and the unwillingness of deputies to take managerial responsibility and implement management systems at the mine site. At Coal Company, the attempt to shift from a flexible discretionary approach to uniform mandatory management standards applying across the board failed not only because some mine managers remained unconvinced of corporate management's commitment or capability and an absence of mine site ownership, but also because of a lack of understanding of what was required to make management-based regulation work at a corporate level, coupled with an organisational history and management philosophy in which a belief in the virtues of decentralisation was deeply embedded. These pathologies were compounded by high levels of mistrust between workers and management at some mines.

On the basis of this study at least, it would appear that corporate systems and other tools of management-based regulation only work well when OHS is institutionalised, and when it gets into the 'bloodstream' of the organisation at site level. Only when the formal systems (audits, reporting, monitoring, and so on) are supported by informal systems (trust, commitment, engagement, means of overcoming conflicting loyalties) will they be fully effective.

These findings have important implications for regulatory theory. They suggest that the claim that management-based regulationor meta-regulation more broadly-can overcome many of the traditional challenges of regulating complex organisations is overstated. On the contrary, this study suggests that management-based regulation (or indeed meta-regulation) confronts much the same challenges as other forms of regulation (albeit on a different scale). The result is that management-based (or meta-) regulation may simply relocate the problems (from outside to inside the firm), rather than solving them. We have insufficient evidence to say whether the mining industry, with its distinctive history of conflict and polarisation, is unrepresentative in 
this respect. In this industry at least, management-based regulation is substantially constrained by low organisational trust, minimal mine site commitment and divided loyalties.

\section{Further reading}

Bennear, LS 2006. 'Evaluating management-based regulation: A valuable tool in the regulatory toolbox?', in C Coglianese and J Nash (eds), Leveraging the Private Sector: Management-based Strategies for Improving Environmental Performance. Washington, DC: Resources for the Future, pp. 51-86.

Hale, A and Hovden, J 1998. 'Management and culture: The third age of safety-A review of approaches to organisational aspects of safety, health and environment', in A Feyer and A Williamson (eds), Occupational Injury: Risk Prevention and Intervention. London: Taylor \& Francis, pp. 129-67. doi.org/10.1201/9780203212493. ch11.

\section{References}

Barling, J and Hutchinson, I 2000. 'Commitment vs control-based safety practices, safety reputation and perceived safety climate', Canadian Journal of Administrative Sciences 17(1): 76-84. doi. org/10.1111/j.1936-4490.2000.tb00208.x.

Bijlsma, KM and Koopman, PL 2003. 'Introduction: Trust within organizations', Personnel Review 32(5): 543-55. doi. org/10.1108/00483480310488324.

Bluff, L 2003. Systematic management of occupational health and safety, Working Paper 20, National Research Centre for Occupational Health and Safety Regulation, Canberra. Available at: digital collections.anu.edu.au/handle/1885/41230.

Braithwaite, V 2008. Defiance in Taxation and Governance. Cheltenham, UK: Edward Elgar. 
Coglianese, C and Lazar, D 2003. 'Management-based regulation: Prescribing private management to achieve public goals', Law and Society Review 37(4): 691-730. doi.org/10.1046/j.00239216.2003.03703001.x.

Coglianese, C and Nash, J (eds) 2006. Leveraging the Private Sector: Management-based Strategies for Improving Environmental Performance. Washington, DC: Resources for the Future.

Dirks, KT and Ferrin, DL 2002. 'Trust in leadership: Meta-analytic findings and implications for research and practice', Journal of Applied Psychology 87(4): 611-28. doi.org/10.1037/00219010.87.4.611.

Gallagher, C 1997. Health and Safety Management Systems: An Analysis of Systems Types and Effectiveness. Melbourne: National Key Centre for Industrial Relations, Monash University.

Galvin, J 2005. 'Occupational health and safety acts: Performance and prosecution in the Australian minerals industry', Mining Technology 114(4): 251-6. doi.org/10.1179/037178405X74086.

Gunningham, N and Sinclair, D 2009. 'Organizational trust and the limits of management based regulation', Law and Society Review 43(4): 865-900. doi.org/10.1111/j.1540-5893.2009.00391.x.

Gunningham, N and Sinclair, D 2012. Managing Mining Hazards: Regulation, Safety and Trust. Sydney: The Federation Press.

Hertin, J, Berkhout, F, Wagner, M and Tyteca, D 2008. 'Are EMS environmentally effective? The link between environmental management systems and environmental performance in European companies', Journal of Environmental Planning and Management 51(2): 259-83. doi.org/10.1080/09640560701865040.

McBarnet, D and Whelan, C 1999. Creative Accounting and the CrossEyed Javelin Thrower. New York: Wiley.

Merton, RK 1968. Social Theory and Social Structure. New York: Free Press.

Morgan, RM and Hunt, SD 1994. 'The commitment-trust theory of relationship marketing', Journal of Marketing 58: 20-38. doi. org/10.2307/1252308. 
Parker, CE 2002. The Open Corporation: Effective Self-regulation and Democracy. Cambridge: Cambridge University Press. doi. org/10.1017/CBO9780511550034.

Reason,J 1997. Managing the Risks of Organisational Accidents. Aldershot, UK: Ashgate.

Schein, EH 1983. 'The role of the founder in creating organizational culture', Organizational Dynamics 12(1): 13-28. doi. org/10.1016/0090-2616(83)90023-2.

Selznick, P 1992. The Moral Commonwealth: Social Theory and the Promise of Community. Berkeley: University of California Press.

Sinclair, A 1993.'Approaches to organisational culture and ethics', Journal of Business Ethics 12(1): 63-73. doi.org/10.1007/BF01845788.

Teubner, G 1983. 'Substantive and reflexive elements in modern law', Law and Society Review 17(2): 239-85. doi.org/10.2307/3053348.

Thomas, M 2011. A systematic review of the effectiveness of safety management systems, ATSB Transport Safety Report, Australian Transport Safety Bureau, Canberra. Available at: atsb.gov.au/ media/4053559/xr2011002_final.pdf.

Thomas, WI and Thomas, D 1928. The Child in America: Behavior Problems and Programs. New York: AA Knopf.

Tyler, TR 2003. 'Procedural justice, legitimacy, and the effective rule of law', Crime and Justice 30: 283-357. doi.org/10.1086/652233.

Tyler, TR 2008. 'Psychology and institutional design', Review of Law and Economics 4(3): 801-86. doi.org/10.2202/1555-5879.1233.

Tyteca, D, Carlens, J, Berkhout, F, Hertin, J, Wehrmeyer, W and Wagner, M 2002. 'Corporate environmental performance evaluation: Evidence from the MEPI project', Business Strategy and the Environment 11(1): 1-13. doi.org/10.1002/bse.312.

Uttal, B 1983. 'The corporate culture vultures', Fortune 108: 66-72. 
This text is taken from Regulatory Theory: Foundations and applications, edited by Peter Drahos, published 2017 by ANU Press, The Australian National University, Canberra, Australia. 